
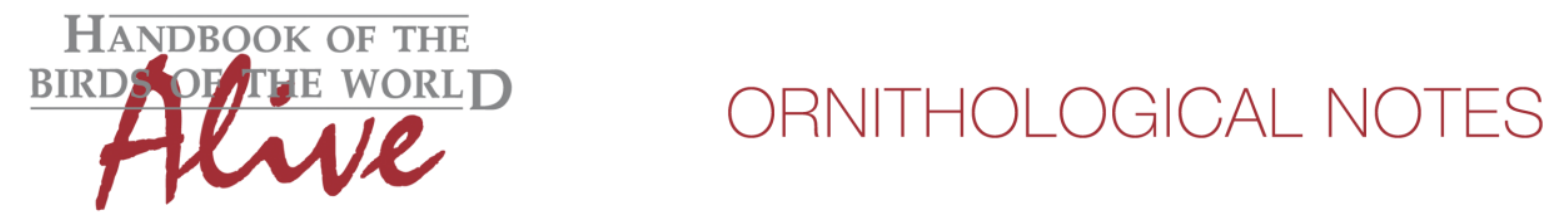

\title{
Notes on the vocalizations of Plain-mantled Tit-spinetail (Leptasthenura aegithaloides)
}

Peter Boesman

In the following we briefly analyze and compare voice of the different races of Plain-mantled Tit-spinetail (Leptasthenura aegithaloides). We also try to quantify the extent of any vocal differences using the criteria proposed by Tobias et al. (2010), as a support for taxonomic review. We have made use of sound recordings available on-line from Xeno Canto (XC) and Macaulay Library (ML).

From the 37 recordings in XC and 11 recordings in $\mathrm{ML}$, divided over 4 taxa (several voice types and several recordings of same bird/same place), it is far from straightforward to draw any conclusions on voice.

It seems that most if not all taxa have at least the following vocalizations:

* a long series of notes (which I assume is the song)

* a short rattled trill

* a short buzzy chatter

In the following I only have compared the 'song'.

It would seem there are three groups of which song can be easily distinguished on sonogram:

Pacific group (aegithaloides and griscescens) (Fig. 1)

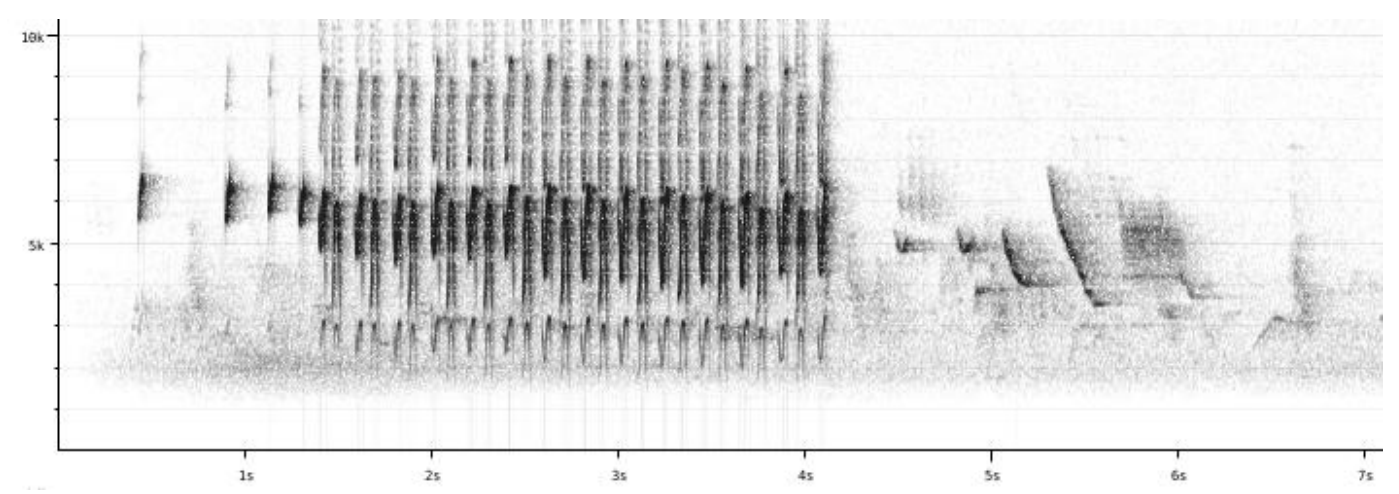

Figure 1: typical 'song' of Pacific group

Measurements:

max freq notes

min freq notes

$4800-5700 \mathrm{~Hz}$

note length

$2600-2900 \mathrm{~Hz}$

pace $(n=5)$

$0.04-0.06 \mathrm{~s}$

ratio note-length/pause

$0.44-0.48$

note shape:

0.6-1

every note has a clearly curly shape

(Jaramillo (2003) states that song of griscescens is quicker and higher-pitched. I could not confirm this (only recording XC60196 of Jaramillo is almost identical to aegithaloides)). 

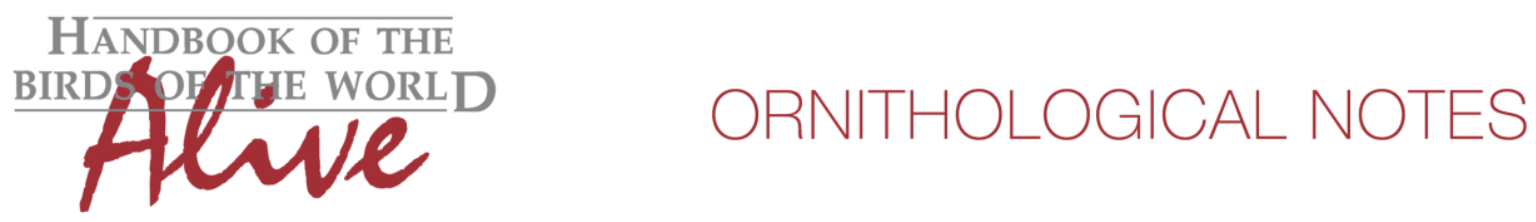

\section{Puna group (berlepschi) (Fig. 2)}

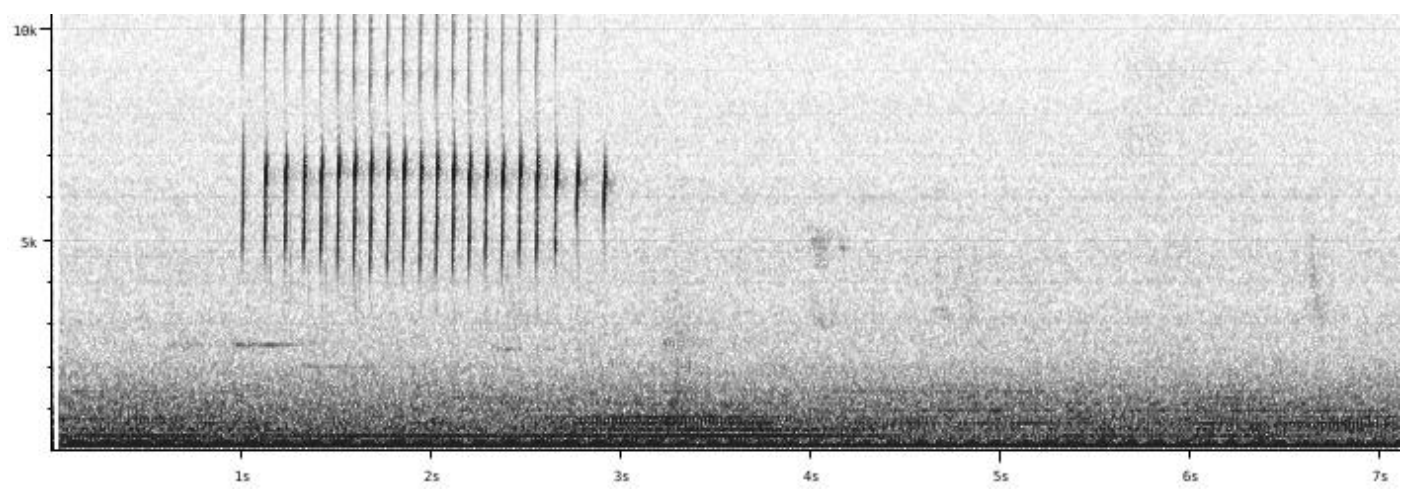

Figure 2: typical 'song' of Puna group

Measurements:

$\begin{array}{ll}\text { max freq notes } & 4800-8000 \mathrm{~Hz} \\ \text { min freq notes } & 2400-4000 \mathrm{~Hz} \\ \text { note length } & 0.012-0.017 \mathrm{~s} \\ \text { pace }(\mathrm{n}=5)^{*} & 0.34-0.4 \\ \text { ratio note-length/pause } & 0.1-0.2 \\ \text { note shape: } & \text { every note is very short and steeply upslurred }\end{array}$

* Pace is measured here as 5 periods: the duration of 5 notes + pauses

\section{Patagonian group (pallida) (Fig. 3)}

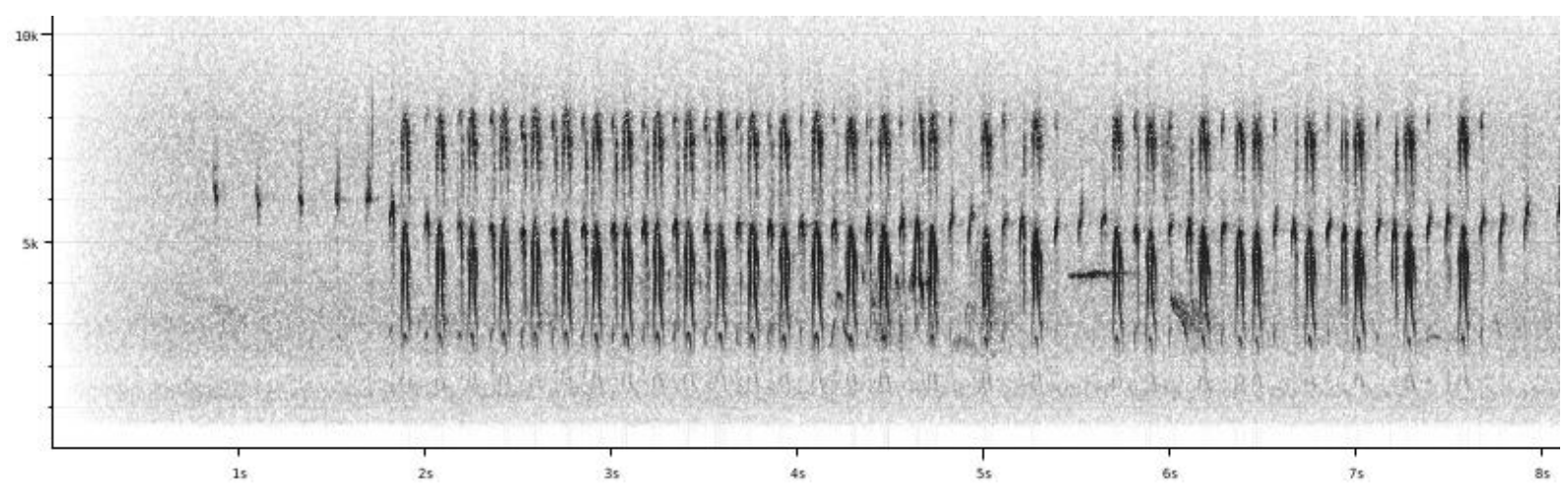

Figure 3: typical 'song' of Patagonian group

Measurements:

max freq notes

min freq notes

note length

pace $(n=5)$

ratio note-length/pause

note shape:

\section{$5200-5500 \mathrm{~Hz}$ \\ $2200-2700 \mathrm{~Hz}$ \\ $0.03-0.05 \mathrm{~s}$ \\ $0.27-0.37$ \\ $1-1.25$}

two distinct notes, one is a perfect overslurred note (with a peculiar lower freq artefact, indicating that actually the first harmonic is by far the loudest one), sometimes alternated with shorter notes which seem to be shortened versions of the previous one, all in all also a very recognizable pattern shared among all recordings of this group (Fig. 4). 

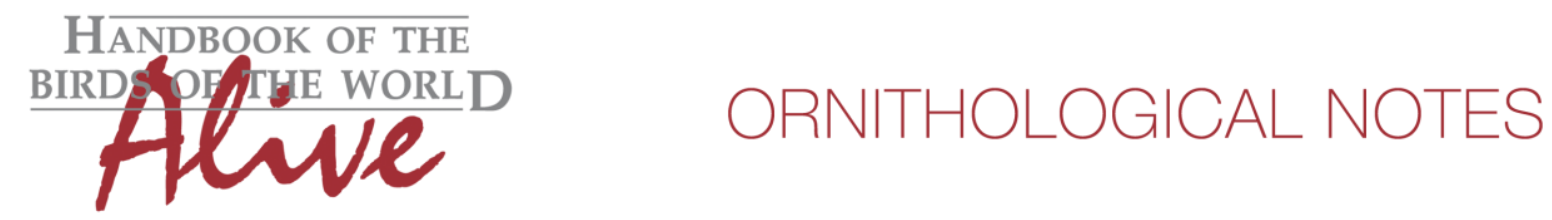

It would thus seem that there are clear vocal differences between the 3 groups:

Pacific group vs Puna group: Pacific group has longer notes (score 3) and a much larger ratio note-length/pause (score 3 ). Note shape is also very different (long and curly vs. short and upslurred)(score at least 2). This would lead to a total vocal score of 5-6 when applying Tobias criteria.

Pacific group vs Patagonian group: In Pacific group, notes are delivered at a slower pace (score 2), also resulting in a smaller ratio note-length/pause (score 2). Note shape (Fig. 4) is also very different (very curled vs. overslurred) (score 2 or 3 ). This would lead to a total vocal score of 4-5.
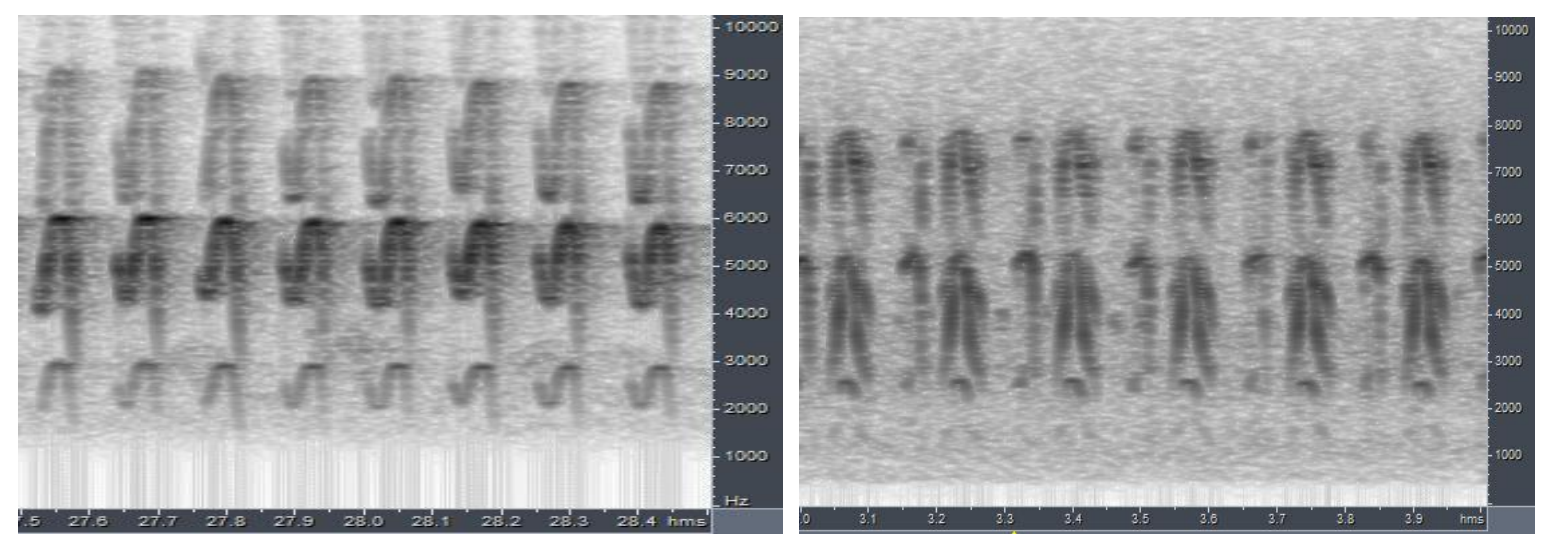

Figure 4: note shape in 'song' of Pacific group (left) and Patagonian group (right)

Puna group vs Patagonian group: In Puna group, notes are much shorter (score 3 ) and ratio note-length/pause is much smaller (score 3 ). Note shape is also very different (short upslurred vs. longer overslurred) (score at least 2). This would lead to a total vocal score of 56 when applying Tobias criteria.

This note was finalized on 10th April 2015, using sound recordings available on-line at that moment. We would like to thank in particular the sound recordists who placed their recordings for this species on XC and ML: Davis Finch, Daniel Gonzalez, Alvarro Jaramillo, Doug Knapp, Niels Krabbe, Bernabe Lopez-Lanus, Aidan Maccormick, Mark Robbins, Fabrice Schmitt, Andrew Spencer, Tomek Tumiel and Felix Vidoz.

\section{References}

Jaramillo, A. (2003) Birds of Chile. Princeton field guides. New Jersey. 


\section{Recommended citation}

Boesman, P. (2016). Notes on the vocalizations of Plain-mantled Tit-spinetail (Leptasthenura aegithaloides). HBW Alive Ornithological Note 94. In: Handbook of the Birds of the World Alive. Lynx Edicions, Barcelona. (retrieved from http://www.hbw.com/node/931989 on 20 July 2016). 